\title{
Evaluation of the Quality of Life in Dementia with a Generic Quality of Life Questionnaire: The Duke Health Profile
}

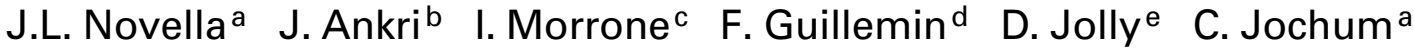 \\ L. Ploton ${ }^{f}$ F. Blanchard ${ }^{a}$ \\ aDepartment of Internal Medicine and Gerontology, Hôpital Sébastopol, Reims, bHôpital Sainte Perine, Paris, \\ 'Reeducation, Hôpital Sébastopol, Reims, 'dSchool of Public Health EA 1124, Vandoeuvre les Nancy, \\ eDepartment of Medical Information, Hôpital Maison Blanche, Reims, and fUniversité Lumières, Bron, France
}

\section{Key Words}

Quality of life · Aging · Dementia - Alzheimer's disease · Duke Health Profile

\begin{abstract}
Objective: The study was designed to determine the acceptability, feasibility and validity of measuring quality of life in a representative sample of dementia patients with a generic instrument, the Duke Health Profile. Method: The French version of the Duke Health Profile was administered to 148 subjects with a mental disorder according to the DSM-III-R diagnostic criteria. The feasibility and acceptability of employing the instrument were determined by the refusal rate, the type of administration, and the percentage and distribution of missing data. Reliability was determined with Cronbach's $\alpha$ coefficient. Instrument reproducibility was assessed with the intraclass correlation coefficient for test-retest values. Internal construct validity was determined by factor analysis. Discriminant capacity was determined by comparing the average scores on each measure among patients with and without an additional chronic pathology. The measurements obtained were compared by source of information (patient, family proxy and care provider proxy). Results: The feasibility and acceptability of the
\end{abstract}

\section{KARGER}

Fax +4161306 1234

E-Mail karger@karger.ch

www.karger.com

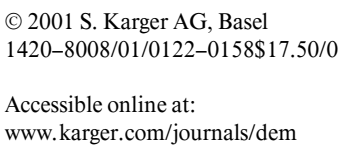

instrument was good. Only $2 \%$ of the patients refused to complete the questionnaire. Help from the interviewer was necessary in $79 \%$ of the cases. The average completion time was $10.6 \mathrm{~min}$. Missing data exist in only $3.5 \%$ of the cases on average, except among patients with severe dementia (Mini Mental State Examination $<10$ ). For reliability, internal consistency was acceptable (Cronbach's coefficient $\alpha=0.5-0.7$ ) when the self-esteem (0.23) and social health (0.26) concepts were eliminated. Reproducibility as measured by test-retest scores was moderate to good (intraclass correlation coefficient $r=0.53-0.80$ ), except for anxiety (0.48) and perceived health (0.45). Severity of dementia mainly affected the feasibility, acceptability and reproducibility of the instrument. The family proxy seemed to agree more with the patient than did the care provider proxy. Conclusion: Quality of life can be measured in patients with dementia, but special tools need to be developed for severe dementia.

Copyright $\odot 2001$ S. Karger AG, Basel

\section{Introduction}

In industrialized countries, people are living longer [1]. With dementia rates of $5 \%$ in people over 65 and $30 \%$ in people over 90 [2], population aging will have an in- 
fluence on pathologies associated with extreme old age, and dementia, for one, will increase substantially. According to demographic projections in France, about 400,000 people will have Alzheimer's disease by 2010 [3].

In the absence of any cure for dementia, we need to be able to rely on instruments to evaluate the care offered to patients. In this respect, indicators of health-related quality of life are valuable [4-6] since they allow researchers, decision makers and pharmaceutical companies [7], as well as clinicians [8], to evaluate the benefits of therapeutic strategies and prevention for a given patient group.

The number of instruments that measure health-related quality of life has grown exponentially in the past 20 years. Excluding instruments for use in observation studies, very few questionnaires have been specifically designed for dementia patients, apart from the Italian Quality of Life Scale [9], Pleasant Event Schedule-AD [10], Progressive Deterioration Scale [11] and Dementia Quality of Life Instrument [12]. These instruments are not available in French, and some of them tend to be nothing but measures of a subject's dependence. The Dementia Quality of Life Instrument is the most recent of these instruments. While it is a good measuring instrument, it has only been validated on subjects with mild to moderate dementia, i.e. with a score of more than 12 on Folstein's Mini Mental State Examination (MMSE) [13]. As for approaching patient quality of life through proxies, this gives only a very indirect evaluation.

The purpose of this study was to evaluate the acceptability, feasibility and validity of employing a generic quality of life questionnaire, the Duke Health Profile, in which a French language version has been validated [14] on a sample of patients with dementia. A preliminary analysis of the instrument's properties in a population of dementia patients produced incomplete but promising results [15]. The Duke Health Profile was selected because it met two criteria: first, it can be administered to any population, and, second, it is short enough for use with dementia patients. A further analysis was made of the effects of the severity of impairment on the instrument's performance.

\section{Methods}

\section{Sample}

To be included in the study, patients had to be over 60 and meet the criteria for a mental disorder as defined by the DSM-III-R. This decision was deliberately pragmatic. Patient inclusion was irrespective of the exact subtype of mental disorder. Patients who were blind or seriously hearing impaired or could not speak French were excluded from the study.

Quality of Life in Dementia
For ethical reasons, inclusion in the study required the patient's consent along with the consent of the family member closest to the patient or a legal proxy when applicable. The study was approved by the Champagne-Ardenne ethics committee.

To ensure a sufficiently large sample, patients were recruited from 16 centers, including 7 university hospital centers (14 in France, 1 in Switzerland and 1 in Belgium). The patients were seen in consultations, were hospitalized in an acute care unit or were institutionalized.

\section{Instrument}

The Duke Health Profile is a generic quality of life instrument [16]. It can be used to evaluate the health or the health-related quality of life in any population, regardless of pathology. In this respect, the fit differs from specific instruments designed to measure quality of life in people with a particular health problem.

The Duke Health Profile is a 17 -item self-administered questionnaire containing 5 independent health concepts: physical health, 5 items; mental health, 5 items; social health, 5 items; perceived health, 1 item; disability, 1 item; and 5 other concepts derived from a recombination of the preceding: self-esteem, 5 items; anxiety, 6 items; depression, 5 items; pain, 1 item, and general health, 15 items. Item 3 explores only perceived health, while item 17 deals only with disability.

Each question has 3 possible answers, rated 0,1 or 2 . Responses to the items in each measure are added together and then the means of the raw item scores are normalized to a scale of 0 (worst) to 100 (best) for physical health, mental health, general health, perceived health and self-esteem, and of 0 (best) to 100 (worst) for anxiety, depression, pain and disability. The subjects' responses are presented in the form of a profile of the scores calculated for each of the 10 concepts, and there is no general score.

\section{Instrument Administration}

Given the subjects' particular characteristics, it was decided that the interviewer could administer the questionnaire if need be. The interviewers at all the centers received 1 day of training in instrument administration prior to taking part in the study. A close family member and a care provider were asked to act as proxies for the patient and complete the questionnaire from the patient's point of view. This made it possible to determine concordance between the proxies and the patient.

The questionnaire was again administered 4 days later to a subgroup drawn at random from the sample ( 1 out of 4 patients) in order to determine the instrument's test-retest reproducibility.

For each patient, the following were systematically noted: sex, age, marital status, school leaving age, family situation, housing arrangements, type of dementia diagnosed, year of diagnosis, comorbidity, any treatment being received and indicators of dementia severity: MMSE [13], and Hughes's Clinical Dementia Rating Scale [17].

In addition, the time to complete the Duke Health Profile and the level of autonomy of each patient according to Katz's Index of Activities of Daily Living were noted [18].

\section{Statistical Analysis}

Feasibility and Acceptability. The refusal rate, type of administration (self-administered or interviewer administered), time for completion, and number and distribution of missing data were used as indicators of the feasibility and acceptability of the instrument. 
Table 1. Patient characteristics at induction into the study

\begin{tabular}{|c|c|c|}
\hline & Males & Females \\
\hline Patients & 28 & 120 \\
\hline \multicolumn{3}{|l|}{ Age, years } \\
\hline Median & 81.5 & 84 \\
\hline Range & $61-89$ & $60-93$ \\
\hline \multicolumn{3}{|l|}{ Living arrangement, $\%$} \\
\hline Home & 25.0 & 11 \\
\hline Hospital & 53.5 & 41 \\
\hline Institution & 21.5 & 48 \\
\hline \multicolumn{3}{|l|}{ Marital status, $\%$} \\
\hline Single & 7.0 & 15 \\
\hline Married & 64.3 & 20 \\
\hline Divorced & 14.3 & 2 \\
\hline Widowed & 14.3 & 63 \\
\hline \multicolumn{3}{|l|}{ School leaving age, $\%$} \\
\hline$<12$ years & 0 & 12 \\
\hline $12-16$ years & 42 & 61 \\
\hline$\geq 16$ years & 61 & 27 \\
\hline \multicolumn{3}{|l|}{ Origin of dementia, $\%$} \\
\hline Alzheimer's disease & 57.0 & 75.8 \\
\hline Vascular & 21.4 & 10.3 \\
\hline Alcoholism & 14.3 & 1.7 \\
\hline Other & 7.3 & 12.2 \\
\hline \multicolumn{3}{|c|}{ Mini Mental State Examination } \\
\hline Median & 12.5 & 13 \\
\hline Range & $2-24$ & $0-24$ \\
\hline \multicolumn{3}{|c|}{ Clinical Dementia Rating Scale, \% } \\
\hline Probable deficit & 7 & 2 \\
\hline Slight deficit & 25 & 23 \\
\hline Moderate deficit & 39 & 41 \\
\hline Severe deficit & 29 & 34 \\
\hline
\end{tabular}

Reliability. Test-retest reliability of each of the 10 scales of the instrument was evaluated by calculating the intraclass correlation coefficient (p) [19] based on a single-factor analysis of variance [20] on a random sample of $25 \%$ of the subjects in the original sample. An intraclass correlation coefficient of $p>0.5$ was considered acceptable and $p>0.7$ was considered good [19]. Internal consistency was estimated, for the 7 multi-item concepts, by computing Cronbach's $\alpha$ interest consistency coefficients [21]. Cronbach's $\alpha$ coefficients $\geq 0.6$ were considered as evidence of an acceptable interest consistency for the considered scale.

Internal Construct Validity. This was determined by a principal component analysis of the 15 items entering into the calculation of more than one measure. Factors were retained if their eigenvalues (a statistical measure of their power to explain variation between patients) exceeded 1 [22]. The contribution of the different factors to represent the data was expressed by the percentage of explained variance. Loading coefficients of the item with each factor were examined. When loading exceeded 0.40 , the item was considered meaningful for the considered factor [23]. A principal component analysis was performed on raw data and after orthogonal varimax rotation of the factors once the number to be retained was determined.
External Construct Validity. The discriminating capacity of the Duke Health Profile was determined by comparing the average measure scores of subjects with and without an additional chronic pathology. For this, an analysis of variance adjusted for the severity of dementia according to the MMSE score was carried out. To evaluate the discriminating capacity for pain, the same analysis was performed on subjects receiving pain relief treatment and subjects not receiving such treatment. The assumption was that treatment indicated a pain syndrome assessed by the physician in charge of the patient.

Concordance between the patients and their proxies in the concepts covered by the questionnaire was evaluated using the intraclass correlation coefficient $\mathrm{p}$ based on a single-factor analysis of variance [20]. A value of $p>0.5$ was considered acceptable and a value of $p>$ 0.7 was considered good [19]. The measure scores for the subjects, family proxies and care provider proxies were compared two by two with the Student test for paired measurements.

The scores of a subgroup of subjects with less severe dementia (MMSE $\geq 15$ ) were analyzed to determine whether the deterioration in higher functions seriously reduced instrument performance. The analyses were performed with BMDP Dynamic.

\section{Results}

A total of 148 patients from 16 centers were selected for the study between June 1997 and April 1998. Their average age was 81.8 years $(\mathrm{SD}=7)$, and women outnumbered men 4 to 1 . The average time since onset of dementia was 3.5 years $(\mathrm{SD}=2.4)$. A more detailed summary of the sample appears in table 1.

It was possible to administer the instrument to $98 \%$ of the subjects, with $20 \%$ completing it on their own. These subjects were significantly less impaired in terms of mean MMSE (19 compared with 11.5: $p<0.01$ ) and average deficit according to Hughes's Clinical Dementia Rating Scale $(1.3$ compared with 2.1: $p<0.001)$. They also had significantly more schooling (17 years compared with 14 : $p<0.01)$. Age was not a discriminating variable for the method of administration: 78 years for self-administered, 82 years for interviewer administered; $p=0.11$.

Average time to complete the questionnaire was 10.6 $\min (\mathrm{SD}=9 \mathrm{~min})$. Missing data represented between 7 and $14 \%$ of the instrument, with 2 items having a higher percentage: item 6 , 'I am satisfied with my family relationships' (17.5\%) and item 17, 'During the past week, how often did you stay in your home, a nursing home, or hospital because of sickness, injury, or other health problems' (26.6\% did not respond). Excluding subjects with an MMSE $\leq 5$, the overall percentage of missing data was 10.3, ranging from 1.6 to 7.0 per item. Again, the highest percentages were for items 6 (9.7) and 17 (15.0). In patients with MMSE $\geq 15$, the percentage of missing data 
Table 2. French Duke Health Profile acceptability according to severity of dementia

\begin{tabular}{|c|c|c|c|c|c|c|}
\hline & \multicolumn{6}{|l|}{ MMSE } \\
\hline & $0-4$ & $5-9$ & $10-14$ & $15-19$ & $20-24$ & Total \\
\hline Patients & 14 & 35 & 45 & 35 & 19 & 148 \\
\hline Refusal of administration & 0 & 2 & 0 & 1 & 0 & 3 \\
\hline \multicolumn{7}{|l|}{ Type of administration, $\%$} \\
\hline Self-administered & 7.7 & 15.2 & 13.3 & 19.2 & 47.4 & 20 \\
\hline Interviewer-administered & 92.3 & 84.8 & 86.7 & 80.8 & 52.6 & 80 \\
\hline \multicolumn{7}{|l|}{ Time to complete, $\min$} \\
\hline Average (SD) & $10.9(7)$ & $11(7)$ & $11(9)$ & $9.4(10)$ & $11.5(12)$ & $10.6(9)$ \\
\hline \multicolumn{7}{|l|}{ Missing data, $\%$} \\
\hline Average (SEM) & $33(10)$ & $25(6.5)$ & $3.8(1.3)$ & $4.7(2.5)$ & $0.6(0.4)$ & $11.2(2.1)$ \\
\hline
\end{tabular}

per item was between 0 and 6 (except for items 6, 10, and 17, 14). This gave a percentage of missing values of 7.4 for physical health, 11.1 for mental health, 9.3 for social health, 22.0 for general health, 3.7 for perceived health, 11.0 for self-esteem, 9.3 for anxiety, 11.1 for depression, 1.9 for pain and 13.0 for disability. Thus, instrument acceptability varied with the severity of the pathology (table 2).

Instrument reliability was rather weak. Only 3 concepts (mental health, general health, and depression) reached a Cronbach coefficient $\alpha \geq 0.7$. The four other concepts were insufficiently reliable (table 3 ). In the subgroup of less severely impaired subjects (MMSE $\geq 15$ ), instrument reliability was not improved.

Test-retest reproducibility was calculated on 44 subjects drawn at random from the 148 in the sample (table 3). The intraclass correlation coefficient was above 0.5 for all the concepts except perceived health $(0.45)$ and anxiety (0.48). In subjects with MMSE $\geq 15$, a score of $<0.5$ was found only for self-esteem.

The factor analysis on the 15 items in multi-item concepts included all the subjects. Five factors had an eigenvalue greater than 1 and explained $59 \%$ of the instrument's total variance (table 4). In the first component, which alone accounted for $23.2 \%$ of the variance, mental health was well represented (4 items with a high loading out of 5). The second component tended to correspond to anxiety (4 items with a high loading out of 6 ) and depression ( 3 items out of 5). The third axis tended to reflect social health ( 3 out of 5) and self-esteem (4 out of 5). The fourth axis gave a satisfactory representation of physical health ( 3 out of 5 ). On the fifth axis, only 2 items, 15 and 16 , had a representation $>0.4$. These 2 items entered into the social health measure. No improvement in these
Table 3. Reliability study of the French version of the Duke Health Profile in dementia

\begin{tabular}{llll}
\hline $\begin{array}{l}\text { French Duke } \\
\text { Health Profile }\end{array}$ & \multicolumn{2}{c}{ All patients } & $\begin{array}{l}\text { Patients with } \\
\text { MMSE }>14 \\
\text { test-retest } \\
(\mathrm{n}=15)\end{array}$ \\
\cline { 2 - 3 } & $\begin{array}{l}\text { Cronbach's } \\
(\mathrm{n}=148)\end{array}$ & $\begin{array}{l}\text { test-retest } \\
(\mathrm{n}=44)\end{array}$ & 0.78 \\
\hline Physical health & 0.58 & 0.75 & 0.75 \\
Mental health & 0.70 & 0.70 & 0.58 \\
Social health & 0.26 & 0.51 & 0.79 \\
General health & 0.70 & 0.77 & 0.56 \\
Perceived health & - & 0.45 & 0.38 \\
Self-esteem & 0.23 & 0.53 & 0.50 \\
Anxiety & 0.5 & 0.48 & 0.61 \\
Depression & 0.68 & 0.61 & 0.69 \\
Pain & - & 0.57 & 0.80 \\
Disability & - & 0.80 &
\end{tabular}

Test-retest reliability evaluated by the intraclass correlation coefficient. Intraclass correlation coefficient and Cronbach's vary between 0 and 1.0, higher values suggesting better reliability.

results was found when only less severely impaired subjects (MMSE $\geq 15$ ) were analyzed.

The discriminating capacity of the Duke Health Profile was determined by the 108 questionnaires in which all 10 concepts had been completed. It was found that subjects with no additional chronic pathology had a better quality of life in 9 of the 10 concepts, with significant differences in 6 of the 10 (table 5). Of the 133 subjects who completed the pain measure, 30 were receiving treatment for pain relief. These subjects had a significantly higher average pain score $(50 / 100)$ than those not receiving such treatment $(31 / 100), p=0.01$. 
Table 4. Identification of factors and their contribution in the principal component analysis performed an the 15 items entering into the calculation of more than one measure: representation of scales and items with their loading on 5 factors after orthogonal rotation varimax

\begin{tabular}{|c|c|c|c|c|}
\hline Factor & $\begin{array}{l}\text { Eigen- } \\
\text { value }\end{array}$ & $\begin{array}{l}\text { Factor } \\
\text { variance, } \%\end{array}$ & $\begin{array}{l}\text { French Duke Scale }{ }^{1} \\
\text { (n) }\end{array}$ & Loading of items \\
\hline 1 & 3.5 & 23.2 & mental health $(4 / 5)$ & $13: 0.74 / 4: 0.71 / 1: 0.58 / 14: 0.48$ \\
\hline 2 & 1.8 & 12 & $\begin{array}{l}\text { anxiety }(4 / 5) \\
\text { depression }(3 / 5)\end{array}$ & $\begin{array}{l}\text { 10: } 0.63 / 12: 0.57 / 5: 0.53 / 14: 0.53 \\
10: 0.63 / 12: 0.57 / 5: 0.53\end{array}$ \\
\hline 3 & 1.3 & 8.5 & $\begin{array}{l}\text { esteem }(4 / 5) \\
\text { social health }(3 / 5)\end{array}$ & $\begin{array}{l}2: 0.73 / 7: 0.71 / 6: 0.62 / 1: 0.52 \\
2: 0.73 / 7: 0.71 / 6: 0.62\end{array}$ \\
\hline 4 & 1.2 & 7.9 & physical health $(3 / 5)$ & $8: 0.84 / 9: 0.56 / 11: 0.43$ \\
\hline 5 & 1.1 & 7.6 & social health $(2 / 5)$ & $15: 0.76 / 16: 0.80$ \\
\hline
\end{tabular}

1 Number of items of the scale with a load $>0.40$ on the corresponding factor.

Table 5. Analysis of variance ${ }^{1}$ on the average measure scores (SD) of the Duke Health Profile for subjects with and without an additional chronic pathology

\begin{tabular}{lllll}
\hline Concepts & All patients & $\begin{array}{l}\text { Without an additional } \\
\text { chronic pathology } \\
(\mathrm{n}=28)\end{array}$ & $\begin{array}{l}\text { With an additional } \\
\text { chronic pathology } \\
(\mathrm{n}=80)\end{array}$ & $\mathrm{p}$ \\
\hline Physical health & $57.3(24)$ & $69.6(21)$ & $53.1(24)$ & $0.002^{*}$ \\
Mental health & $63.0(27)$ & $72.5(21)$ & $59.8(28)$ & $0.03^{*}$ \\
Social health & $53.0(17)$ & $50.5(17)$ & $53.8(18)$ & 0.30 \\
General health & $57.7(17)$ & $64.2(15)$ & $55.5(18)$ & $0.025^{*}$ \\
Perceived health & $65.1(39)$ & $67.8(41)$ & $63.7(39)$ & 0.40 \\
Self-esteem & $64.8(19)$ & $68.9(14)$ & $63.2(20)$ & 0.16 \\
Anxiety & $41.7(21)$ & $61.6(18)$ & $57.3(22)$ & 0.34 \\
Depression & $38.8(27)$ & $70.7(24)$ & $58.2(28)$ & $0.04^{*}$ \\
Pain & $36.7(37)$ & $78.6(34)$ & $58.7(36)$ & $0.01^{*}$ \\
Disability & $50.0(48)$ & $75.0(42)$ & $41.9(48)$ & $0.001^{*}$ \\
\hline
\end{tabular}

Normalized scores 0 (worst) to 100 (best). $* \alpha<0.05$.

1 Analysis of variance was adjusted to the severity of dementia according to the MMSE score.

The average scores for each of the 10 concepts explored in the Duke Health Profile reflected in general the average health of the patients in this study. The scores were calculated in three different ways: by the patients themselves, by the family proxies and by the care provider proxies. The proxies tended to give a lower rating of the patients' state of health on 9 out of 10 concepts than the patients themselves did. The only exception was social health (fig. 1). A two-by-two matched comparison of the concepts showed that only social health $(\mathrm{p}=0.48)$, pain $(\mathrm{p}=$ $0.74)$, and disability $(p=0.29)$ were not evaluated significantly differently by the subjects and their family proxies.
Between the patients and their care provider proxies, social health $(p=0.96)$, pain $(p=0.92)$, disability $(p=$ $0.14)$, and depression $(p=0.14)$ were not rated significantly differently.

As for the two proxies, the only significant differences in their ratings were in mental health $(p=0.009)$ and depression $(\mathrm{p}=0.03)$.

The interrater agreement for the entire sample was poor to mediocre, except in disability, where the intraclass correlation coefficient was 0.55 for the three raters and 0.57 between patients and their family proxies (table 6). When subjects with MMSE $\geq 15$ were compared with their family proxies (table 6 ), the intraclass correla- 
Fig. 1. Mean score of quality of life with normalized scores 0 (worst) to 100 (best).

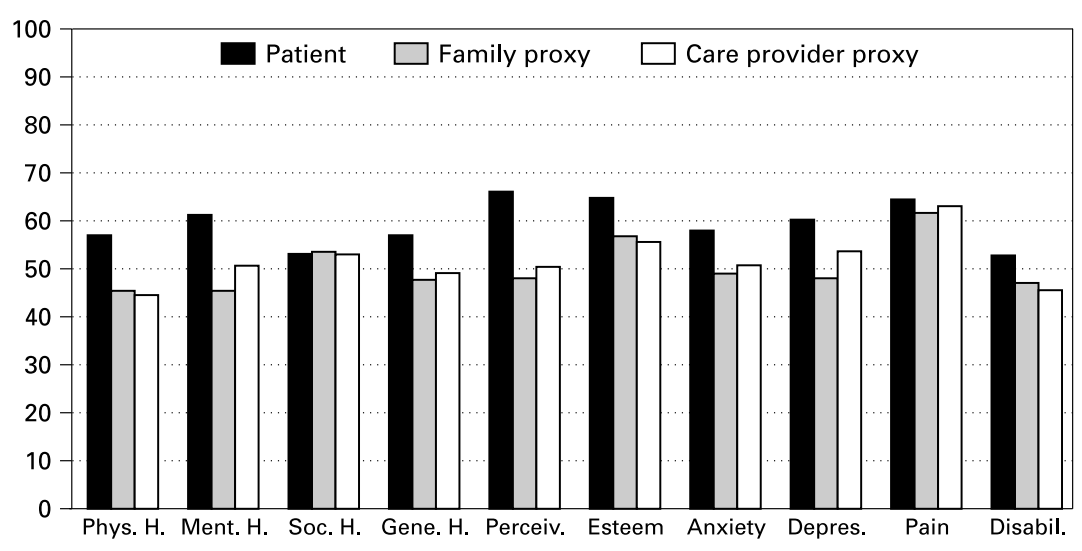

Table 6. Concordance between the patients and their proxies in the concepts covered by the questionnaire evaluated using the intraclass correlation coefficient $\rho$

\begin{tabular}{|c|c|c|c|c|c|c|}
\hline & \multicolumn{3}{|c|}{ All patients $(n=148)$} & \multicolumn{3}{|c|}{ MMSE $>14(n=54)$} \\
\hline & A & $\mathrm{B}$ & $\mathrm{C}$ & A & B & $\mathrm{C}$ \\
\hline Physical health & 0.41 & 0.33 & 0.28 & 0.55 & 0.62 & 0.45 \\
\hline Mental health & 0.32 & 0.30 & 0.17 & 0.50 & 0.66 & 0.34 \\
\hline Social health & 0.22 & 0.15 & 0.19 & 0.23 & 0.27 & 0.15 \\
\hline General health & 0.33 & 0.29 & 0.26 & 0.61 & 0.74 & 0.48 \\
\hline Perceived health & 0.21 & 0.03 & 0.17 & 0.29 & 0.09 & 0.37 \\
\hline Self-esteem & 0.27 & 0.25 & 0.18 & 0.53 & 0.63 & 0.48 \\
\hline Anxiety & 0.22 & 0.15 & 0.19 & 0.41 & 0.45 & 0.25 \\
\hline Depression & 0.31 & 0.23 & 0.21 & 0.39 & 0.54 & 0.17 \\
\hline Pain & 0.30 & 0.31 & 0.21 & 0.34 & 0.47 & 0.19 \\
\hline Disability & 0.55 & 0.57 & 0.46 & 0.57 & 0.61 & 0.36 \\
\hline
\end{tabular}

$\mathrm{A}=3$ judges: patient, family proxy, care provider proxy; $\mathrm{B}=2$ judges: patient, family proxies; $\mathrm{C}=2$ judges: patient, care provider proxies.

tion coefficient was above 0.6 for 5 of the 10 concepts (physical health, mental health, general health, selfesteem and disability). Agreement between the subjects in this subgroup and their care provider proxies was clearly less good, with an intraclass correlation coefficient below 0.5 for all the concepts (table 6 ).

\section{Discussion}

There are three advantages to the Duke Health Profile. This profile of health-related quality of life does not reduce quality of life to a single score, but instead breaks it down and evaluates certain elements that make up healthrelated quality of life. This seems to be a more rigorous approach [24]. There is a validated French adaptation that has been used in subjects over the age of 60 [14]. Furthermore, it does not take long to complete $(10 \mathrm{~min})$ and therefore can be used with people with a limited capacity to concentrate.

This study has shown the interest and limitations in using this type of instrument with persons with dementia. As for the feasibility of its use, the questionnaire was administered in the usual way, i.e. self-completed by $20 \%$ of the sample. These subjects were less severely impaired and had spent more time at school. For the other subjects, the interviewer's help was needed, giving an overall instrument acceptance rate of $98 \%$. While some bias might have been introduced by the interviewer serving as a filter between the patient and the questions, there is 
some debate over the advisability of employing only a self-administered questionnaire to collect information [25]. Some studies have found no differences between self-completed and interviewer completed instruments $[26,27]$.

Instrument acceptability tended to be good if subjects with severe dementia (MMSE $\leq 5$ ) were excluded. This type of questionnaire is not advisable for such patients since the percentage of missing data is too high (from 33 to 67 per item). In the questionnaire tested, items 6 and 17 posed problems. Item 17 drew on short-term memory and proposed an ordinal temporal variable for the response. This is difficult for a patient with dementia to handle. Item 6 involved a value judgement about the patient's family, and the patients had problems answering it. The acceptability of the instrument among patients with an MMSE $\geq 15$ brought out some of the limitations of this questionnaire as compared with a specific instrument such as the Dementia Quality of Life Instrument [12], where the percentage of data missing per scale ranged from 4.2 to 8.4 .

It did not take the subjects in the sample very long to complete the Duke Health Profile (average of $10 \mathrm{~min}$ ). This is a definite advantage with this population, which has limited powers of concentration.

The reliability of the instrument was found to be good for mental health, general health and depression (Cronbach's coefficient $\alpha>0.65$ ), i.e. the patients responded consistently to items making up a single measure. As for the other four concepts, the results were acceptable for physical health and anxiety (Cronbach's coefficient $\alpha>$ 0.50 ), but poor when it came to social health and selfesteem. In the general population, these two concepts have the least internal consistency, with scores of 0.54 and 0.63 , respectively.

Nevertheless, reproducibility of the instrument is good (table 3), and even better with less severe dementia. The only exception to this was found for self-esteem.

The analysis of discriminate capacities involved a comparison between the patients' subjective ratings and the physician's evaluation of their condition. The fact that dementia patients with one or more additional pathologies considered their health less good on 6 of the 10 concepts, and at a significant level, demonstrates the instrument's capacity to distinguish different situations. In this, there is no difference between subjects with and without dementia. It has been shown with the same instrument, but in the general population, that the presence of a chronic pathology significantly affects health-related quality of life scores on 9 of the 10 concepts [14]. That study was based an a sample of 963 subjects and therefore provided a more powerful comparison than here. In the sample examined in this study, patients receiving treatment for pain relief reported significantly more pain. Assuming that such treatment implies an external evaluation of pain (by the physician), the instrument is capable of evaluating the existence of a painful condition in this population.

The instrument's internal construct validity with a sample of dementia patients is satisfactory. The factor analysis on the 15 items associated with the 7 multi-item concepts produced 6 distinct concepts. Only general health could not be individualized, but that was expected because it represents an average of the physical, mental and social health concepts.

Because of the nature of dementia and the expected impairment of cognitive function that characterizes it, the study design called for proxies as well as patients to be questioned. A similar methodology used with cancer patients revealed poor agreement between patient and care provider responses $[28,29]$. That finding and the reliability of higher cognitive functions in the patients included in the study led the authors to conclude that only the patient was in a position to evaluate his or her health-related quality of life. Teri et al. found a lack of concordance unrelated to dementia severity between patients and their family proxies [30]. This study has confirmed poor concordance but, like Magaziner et al. [31], found it to be less marked with less severe pathology. The main advantage in employing a proxy is to reduce missing data on the subject, but there are differences between proxies. Their emotional investment and time spent with the patient are not identical; this might explain some of the lack of concordance. Differences were found in the raters' scores on each of the concepts. While the proxies tended to agree with each other, they did not agree with the patient's ratings. In general, agreement between the patient and family proxy was better than between the patient and the care provider proxy on all the dimensions (table 6). The discrepancy was stronger with less severely impaired patients (MMSE $\geq 15$ ), where the intraclass correlation coefficient between patients and family proxies was above 0.5 for 6 concepts, but never exceeded this level between patients and care provider proxies. The above observations indicate consistency in the measurements made on dementia patients, provided that severe cases are excluded. Thus, this study confirms the findings of Kiyak et al. [32] and Parmelee et al. [33] that dementia patients can be questioned directly. It is therefore appropriate to say that in dementia, as in other chronic pathologies, the patient is 
the best judge of his or her health-related quality of life. However, with dementia patients, the family proxy remains the best source of information for care providers.

Overall, this study confirmed that quality of life can be evaluated in dementia patients. While the severity of dementia has little effect an the reliability or validity of the instrument, it affects its reproducibility and, to a greater extent, acceptability. These results are consistent with those of McHorney [34]. With the Duke Health Profile, concepts as subjective as self-esteem and perceived health are rather poorly evaluated, but that reflects on the instrument's capacity to target these concepts in dementia patients as much as on the patients' ability to communicate their feelings.

\section{Conclusions}

Dementia patients, at least those not severely impaired, are capable of evaluating their health-related quality of life through a questionnaire. While the Duke Health Profile is a good exploratory instrument, it is inadequate for studying perceived health and self-esteem, which are, after all, important concepts of a patient's quality of life. It should be possible to refine the instrument with more suitable questions and thereby improve its validity. But even with improvements, the questionnaire will have limitations, especially in advanced stages of dementia. A nonverbal approach to health-related quality of life would probably provide different and complementary information. This study therefore constitutes the first step in a broader and more specific approach to health-related quality of life in this population.

\section{Acknowledgements}

We are grateful to Prof. Franco, Prof. Metais, Prof. Gonthier, Dr. Magnier, Dr. Munch, Dr. Feteanu, Dr. Wong, Dr. Pellerin, Dr. Strubel, Dr. Wagner, Dr. Dejace, Dr. George, Dr. Clavijo, Dr. Catteau, Dr. Ploton and the European Commission DG V, INSERM, the Regional Council of Champagne-Ardenne, the 'Recherche et Partage' foundation and the 'Régate' association.

This study was funded by: the European Commission DG V, Contract No. SOC9720161805F03 (97CVVF34180), INSERM (Contract No. 4R002C), the Regional Council of ChampagneArdenne, the 'Recherche et Partage' foundation, the 'Régate' association.

\section{References}

1 Campion E: Aging better. N Engl J Med 1998; 338:1064-1066.

2 Hofman A, Rocca W, Brayne C: The prevalence of dementia in Europe: A collaborative study of 1980-1990 findings. Int J Epidemiol 1991;20:734-748

3 Hauw JJ, Dubois B, Verny M, et al: Epidemiologie; in John Libbey Eurotext (ed): La Maladie d'Alzheimer. Pathologie Science Formation. Paris, 1997, pp 19-25.

4 Blanchard F, Bocquet P, Goncalves S, Jolly D, Kariger E, Zawadzki I, Blique S, Ploton L: Les soins relationnels améliorent-ils la qualité de vie des déments? Gérontol Soc 1995;72:156166.

5 Fletcher A, Dickinson E, Philip I: Review: Audit measures: Quality of life instruments for everyday use with elderly patients. Age Ageing 1992;21:142-150.

6 Armstron-Esther CA, Brown KD, McAfee JG: Elderly patients: Still clean and sitting quietly. J Adv Nurs 1994;19:264-271.

7 The Lancet: Quality of life and clinical trials (editorial). Lancet 1995;346:1-2.

8 Brioul M: L'évaluation de la qualité de vie: Un enjeu pour la clinique. Santé Publique 1997;3: 315-328.

9 Bottini GV: Oxiracetam in dementia: A double-blind placebo-controlled study. Acta Neurol Scand 1992;86:237-241.
10 Teri L, Logsdon R: Identifying pleasant activities for Alzheimers disease patients: The Pleasant Events Schedule-AD. Gerontologist 1991; 31:124-127.

11 DeJong R, Osterlund OW, Roy GW: Measurement of quality-of-life changes in patients with Alzheimers disease. Clin Ther 1989;11:545554.

12 Brod M, Stewart A, Sands L, Walton P: Conceptualization, and measurement of quality of life in dementia: The Dementia Quality of Life Instrument (DQoL). Gerontologist 1999;39: 25-35.

13 Folstein M, Folstein S, McHugh P: 'Mini mental state' - a practical method for grading the cognitive state of patients for the clinician. J Psychiatr Res 1975;12:189-198.

14 Guillemin F, Paul-Dauphin A, Virion J, Bouchet C, Briançon S: Le profil de Santé de Duke: Un instrument générique de mesure de qualité de vie liée à la santé. Santé Publique 1997;9: 35-44.

15 Novella J-L, Jolly D, Ankri J Vitry F, Guillemin F, Canas F, Montani C, Dejace A, Metais P, Geoge M, Blanchard F: Analyse préliminaire des propriétés psychométriques du profil de santé de Duke sur un échantillon de 148 sujets atteints de démence. Ann Gérontol 1999;13: 144-155.
16 Parkerson GR, Broadhead WE, Tse CJ: The Duke Health Profile: A 17-item Measure of Health and Dysfunction. Med Care 1990;28: 1056-1072.

17 Hughes C, Berg L, Danziger W, Coben L, Martin R: A new clinical scale for the staging of dementia. Br J Psychiatry 1982;14:566-572.

18 Katz S, Down T, Cash H, Grotz R: Progress in development of index of ADL. Gerontologist 1970;10:20-30.

19 Fermanian J: Mesure de l'accord entre deux juges: Cas quantitatif. Rev Epidémiol Santé Publique 1984;32:408-413.

20 Schrout P, Fleiss J: Intraclass correlations: Uses in assessing rater reliability. Psychol Bull 1979;86:420-428.

21 Cronbach L: Coefficient alpha and the internal structure of tests. Psychometrika 1951;16:297334.

22 Jolliffe I: Principal Component Analysis. New York, Springer, 1986.

23 Pouchot J, Guillemin F, Coste J, Brégon C, Sany J: French quality of life in rheumatology group. Validity, reliability and sensitivity to change of a French version of the Arthritis Impact Measurement Scale 2 (AIMS2) in patients with rheumatoid arthritis treated with methotrexate. J Rheumatol 1996;23:52-60.

24 Rockwood K: Qualité de vie et maladie d'Alzheimer. Alzheimer Actual 1996;106:8-10. 
25 Fallowfield L: Quality of quality-of-life data. Lancet 1996;348:421-422.

26 Cook D, Guyatt G, Juniper E, Grifth L, McIlroy W, Willan A, Jaeschke R, Epstein R: Interviewer versus self-administered questionnaires in developing a disease-specific, health-related quality of life instrument for asthma. J Clin Epidemiol 1993;36:529-534.

27 Weinberger M, Oddone E, Samsa G, Landsman P: Are health-related quality-of-life measures affected by the mode of administration? J Clin Epidemiol 1996;49:135-140.
28 Slevin M: Quality of life: Philosophical question or clinical reality? BMJ 1992;305:466469.

29 Sneeuw K, Aaronson N, Osoba D, Muller M, Hsu M-A, Yung A, Brada M, Newlands E: The use of significant others as proxy raters of the quality of life of patients with brain cancer. Med Care 1997;35:490-506.

30 Teri L, Wagner A: Assessment of depression in patients with Alzheirner's disease: Concordance among informants. Psychol Aging 1999; 6:280-285.

31 Magaziner J, Simonsick E, Kashner T: Patientproxy response comparability on measures of patient health and functional status. J Clin Epidemiol 1988;41:1065-1074.
32 Kiyak HA, Teri L, Borson S: Physical and functional health assessment in normal aging and in Alzheimers disease: Self-report vs family reports. Gerontologist 1994;34:324-330.

33 Parmelee P, Katz I, Lawton MP: Depression among institutionalized aged: Assessment and prevalence. J Gerontol 1989;44:M22-M29.

34 McHorney CA: Measuring and monitoring general health status in the elderly persons: Practical and methodological issues in using the SF-36 Health Survey. Gerontologist 1996; 36:571-583. 